Swarthmore College

Works

$1-1-2014$

\title{
Two Political Sciences Or One? Liberal Arts Political Science As A Disciplinary Partner
}

Richard M. Valelly , '75

Swarthmore College, rvalell1@swarthmore.edu

Follow this and additional works at: https://works.swarthmore.edu/fac-poli-sci

Part of the Political Science Commons

Let us know how access to these works benefits you

\section{Recommended Citation}

Richard M. Valelly , '75. (2014). "Two Political Sciences Or One? Liberal Arts Political Science As A Disciplinary Partner". Polity. Volume 46, Issue 1. 150-156. DOI: 10.1057/pol.2013.34

https://works.swarthmore.edu/fac-poli-sci/90

This work is brought to you for free by Swarthmore College Libraries' Works. It has been accepted for inclusion in Political Science Faculty Works by an authorized administrator of Works. For more information, please contact myworks@swarthmore.edu. 


\title{
Two Political Sciences or One? Liberal Arts Political Science As A Disciplinary Partner
}

\author{
Rick Valelly \\ Swarthmore College
}

This essay sketches the ways that the practices of political science at top R1 institutions and at leading liberal arts colleges differ. But one also can see the two practices as partners in a common enterprise of making political science rigorous, relevant, and clear. This article outlines such a collaboration.

Polity (2014) 46, 150-156. doi:10.1057/pol.2013.34; published online 28 October 2013

Keywords political science as a vocation; normal science; humanistic political science; two cultures; professionalism; pedagogy

Think for a second about political science at an NYU or an MIT. That kind of political science is defined by research programs and graduate instruction. Then imagine it at a place like Macalester or Swarthmore College-that is, at a really good liberal arts college where good teaching matters (indeed where research political scientists often send their children so that they will get such teaching). That political science is about explication, discussion, writing, and acquiring lasting insights. We're talking about two different things, aren't we-a social science in one place, something much closer to the humanities at the other? In fact, they seem different enough to be a special case of C. P. Snow's "two cultures," the sciences and the humanities. ${ }^{1}$

The inference of fundamental difference is perfectly understandable. But I want to suggest that the two political sciences are actually symbiotic. The interdependence already exists for many of us. I believe that we ought to explicitly recognize and foster it.

A collaboration between "the two political sciences" may strike some as perilous. Joan Cocks argues forcefully in this issue that convergence runs the risk of smothering politics as a liberal art. Preston Smith's contribution also speaks to this problem. I take a more hopeful view.

But first another look at the differences. Political science at a liberal arts college (LAC) department differs from its seemingly distant cousin at an R1 department in at least two ways. One basic contrast, already touched on, is the much greater 1959).

1. C.P. Snow, The Two Cultures and the Scientific Revolution (Cambridge: Cambridge University Press, 
emphasis on class time and close engagement with undergraduates. At LACs we teach students who are not on a professional career track in political science. Thus we never have opportunity to brag, as some R1 scholars do, about how we "only" teach 3 or 2 courses, as if our success or status were indexed by how little we are "forced" to teach. But we really wouldn't choose such bragging rights. We consider political science a grand intellectual tradition as much as it is a normal science. Through our immersion in its enduring works, and through absorbing the newest work in published form, we continually revisit basic and still unsettled questions about regimes, human nature, and political behavior. In turn, the pleasure and stimulation of doing that allows us to pass the same bug along to our students just as they are beginning to think seriously about the political world.

Teaching at Swarthmore has indeed broadened me and made me much more tolerant of different schools and approaches in political science than I was when I occupied a particular subfield niche at a big department. Learning how to teach Congress, or rational-choice institutionalism, or the presidency, or parties and elections-all of that effort over the years has given me the opportunity to master works and literatures that I probably would have left alone if I had remained highly specialized in my subfield (which happens to be American political development).

Additionally, the lack of pressure to publish after tenure has actually made publishing after this career milestone more rewarding than it might have been had I stayed at an R1 school. My perch at Swarthmore gave me all of the time that I needed to do my book, The Two Reconstructions, more or less right. ${ }^{2}$ I didn't worry about rushing it along so that I could get promoted or get a pay raise or land a Competing Offer that I could march into my department chair's office.

I've found it easier to reach across disciplines. I've been able to learn a great deal from a statistician here at Swarthmore, Phil Everson, whose accessibility, brilliant mind, and exceptional clarity have given me insight into some of the more mathematically imposing achievements of people in my own profession, principally the pioneering work of Nolan McCarty, Keith Poole, Boris Shor, and Howard Rosenthal. Phil has also introduced me to Bayesian thinking. That's helped me in all kinds of ways-for instance, it helps me to understand Nate Silver's great success in calling the 2012 presidential election. If I had stayed at MIT, where I began my career, no statistician would have given me so much as five minutes of his or her time unless I was already at his or her level.

A second basic contrast-besides the much greater presence of teaching and broad reading in our lives-is a much reduced emphasis on professionalism. I have mixed feelings about this, I must admit. The price of spending so much time in teaching is spending much less time in colloquia and workshops. The

2. Richard M. Valelly, The Two Reconstructions: The Struggle for Black Enfranchisement (Chicago: University of Chicago Press, 2004). 
trade-off for a scholar like me is not really between teaching and research, as is often imagined by scholars at R1 schools. Swarthmore and its peer institutions support research quite generously. The real trade-off is between teaching, on the one hand, and regularly interacting with an institutional infrastructure geared towards the collection of data and the very rapid dissemination of research and initial findings.

Political scientists in top R1 departments routinely interact with an expensive institutional infrastructure (one that we lack at LACs) that ceaselessly cues them to think about "the cutting edge" as opposed to enduring or likely-to-be classic work. They offer training in methods and constantly update technical advances in that training. Their departments, their affiliated centers, and their universities regularly run surveys, and support the collection, maintenance, and dissemination of important and costly datasets. Their university libraries are extremely rich.

Also, there are monthly, bi-weekly, or weekly speaker series across the various subfields, each staffed by graduate students who greet interesting people at the airport and then shuttle them back to campus for a round of conversations one-onone with members of the department. The visitors then proceed to a colloquium to present exciting and important new research or ingenious (and nicely solved) formal models. The department in a major research university is much like a train station: people come in and out all of the time, carrying ideas, powerful methodological and technical breakthroughs, and research findings.

There are regular job searches because people often leave, either in pursuit of professional glory or because they are told to leave (no second book! not enough articles!), and they need to be replaced. Lines are added if the chair is doing a good job. University political scientists are thus often evaluating dossiers, discussing how job talks went and debating whether a potential hire will help to put the department on the professional map or make its spot on the map look bigger. As a result they are constantly assessing where the field is going and trying to place bets on its direction. Finally, of course, R1 political scientists at a top school such as Columbia or Stanford regularly discuss research design and evaluate original research findings and analyses by Ph.D. candidates. They also invest enormous effort in the recruitment of promising Ph.D. candidates.

One might wonder, reading this, whether I am overlooking the colloquia near my small college town. Shortly after I accepted my job offer at Swarthmore I happened to have lunch with a Harvard scholar who acted stunned by the news that I was leaving MIT for a little liberal arts college and who pompously demanded to know what I would do for "ideas." "You'll have to go to Princeton!" he bellowed. I had to refrain from punching him in the nose. Many years later I came to recognize that behind his irritating demeanor there was useful advice. And it is hard to follow: there really isn't time in my schedule, when I'm teaching, to get to Penn or Temple, much less Princeton. My fallback is getting involved in 
conferences-and that helps a lot. But it's not the same thing as the immensely stimulating experience that I had when I was at Princeton for a year, where I indeed received and developed a ton of good ideas! Every Thursday there was a first-rate, technically proficient presentation of fresh research over lunch. Listening and asking questions, I felt as if I was test-driving a Maserati or Ferrari every week.

We would seem, in short, to be talking about two ways of doing political science, not one. But there is a partnership that many of us at LACs engage in-and to my mind it is a valuable connection. It proceeds from a fundamental assumption that you may have already noticed in what I'm saying: namely, that there is only one good way to get how politics actually works and why it works the way it does. That's political science. Not literature, not film, not videos, not punditry. Political science.

This assumption isn't strongly and universally shared, however. Many LAC professors will teach with pieces from The Atlantic or other excellent political journalism, or with memoirs, or even via film and television series. I've often been tempted to illustrate political ambition with Robert Penn Warren's magnificent novel about Huey Long, All The King's Men. We offer a less "professional" syllabus because we believe-correctly, since so few of our students will go on to be professional political scientists-that through our teaching we are assisting the cultivation of a civic imagination. But what if a student is reading a New York Times story that shows the growing gap in congressional party median DW-NOMINATE scores since the 1950s? How will the student know what's going on unless I have discussed the new political science of polarization and the fascinating story of the measures that we have for such polarization? ${ }^{3}$

Indeed, a transformation in our public sphere has occurred: pundits and journalists now consume and report advanced political science, and political scientists are blogging at a growing rate. There are scores of first-rate political science blogs available to our undergraduates (and to journalists). Many of the economics majors in our classes come to our courses with a developed taste for economics blogs, where they will encounter cross-references to political science blogs.

Meanwhile, the monographic literature and journal output of political science has steadily grown-and steadily improved. Political scientists are doing new things with new datasets. And political scientists are also doing new things with old datasets. As someone who works in American political development I eagerly look forward to the results of the pioneering reconstruction of the early Gallup polls undertaken by Eric Schickler, Adam Berinsky, and Devin Caughey. ${ }^{4}$ They are using

3. For more, see Phil Everson, Rick Valelly, and Jim Wiseman, "A Primer on NOMINATE and Voteview," available at http://www.swarthmore.edu/SocSci/rvalell1/works.html, (accessed September 21, 2013).

4. For more, see http://igs.berkeley.edu/schickler/public-opinion.html, http://web.mit.edu/caughey/ www/Site/Research.html and http://web.mit.edu/berinsky/www/research.html, (accessed September 21, 2013). 
the results to re-evaluate the making of New Deal liberalism and the origins of conservatism.

We owe our students a grasp of the ferment and excitement in contemporary political science, and an appreciation of how the discipline is today the best it has ever been at mapping the characteristics of political regimes, including American democracy. The students' capacity to be good citizens depends (rather more than we tend to tell ourselves at liberal arts colleges) on knowing that R1 political science is very much up to the job of answering important questions about politics.

Take two currently urgent questions about American politics: why has income inequality grown, and what does it mean for democracy? Americanists have developed fresh findings and arguments about these questions, and show no sign of stopping their work on them. Our students must be told about these efforts-and about similar achievements, such as the proliferation of online datasets that they can access to understand electoral behavior or congressional problem-solving, and the Cooperative Congressional Election Studies, which have radically lowered the cost of fielding a survey. Telling our students that political science is posing and answering questions that they need to think about in order to be good citizens-or to be good political scientists should they choose-is a large part of what I mean by a partnership between R1 and LAC political science.

Here is where another aspect of the bond between LAC and R1 political science comes in. LAC political science can be, and in many institutions already is, $a$ constituency for clarity and accessibility. As Robert Keohane has written in a fine piece titled, "Political Science as a Vocation":

National and global reputations are built principally on written work, not on teaching. But when we look around, we see that virtually all top-ranked political scientists in the world today are active teachers. Few of them have spent their careers at research institutes or think tanks... [T] here is a reason for this. Teaching undergraduates compels one to put argument into ordinary language, accessible to undergraduates - and therefore to people who have not absorbed the arcane language of social science.

Keohane is surely describing the experience of lecturing to (as opposed to discussion with) undergraduates. When he next discusses teaching graduate students, he describes much of what we at liberal arts colleges also experience: "Teaching graduate students exposes one to new ideas from younger and more supple mindsas long as the students are sufficiently critical of the professor's views."

5. Robert O. Keohane, "Political Science as a Vocation," PS: Political Science \& Politics 42 (April 2009): $359-63$. 
At LACs, we experience both rewards. We have to be accessible to demonstrate why political science offers the best way to understand politics, and we find ourselves challenged by younger, supple minds. This means that we do something essential for the discipline of political science: we constantly "road test" its latest and best work. As a result we see, or our students discover for us, new things in the books or articles that we admire: strengths that we had not noticed before and weaknesses or even methodological errors that our admiration for the work and the authors had previously obscured.

To sum up, the affiliation that I have sketched has two sides to it. First, R1 political science is constantly generating exciting discoveries that we can-indeed, must-use in our teaching. Many of us at LACs with active research and publication programs participate in that enterprise. Second, because we translate and refine that constantly changing mix of new work in our teaching we are not only quite enjoyably "keeping up" with the profession. We are also a permanent constituency for intelligibility in political science-a counterweight against the inevitable pressures for jargon and sometimes needless methodological wizardry.

But here we get to an uncomfortable fact about the LAC professoriate in political science: much of it is estranged, to one degree or another, from the mainstream. Many LAC professors pride themselves on their withdrawal from professional engagement and consider such involvement a distraction from the large and permanent questions of political inquiry. Rather than seeing political science as offering a feast of pedagogical and intellectual riches, we instead, even at the very best colleges, tend to acquire doubts about the utility of mainstream political science the longer that we teach undergraduates. APSA's internal statistics show that our APSA membership rates are sharply lower than that of faculty at Ph.D. granting departments. Furthermore, these rates drop as we move up the ranks from assistant to full professor. (Here I am referring specifically to professors at LACs, not community colleges or state teaching universities, such as the California State University system.) Only a very small fraction of us belong to organized sections of the APSA. Few of us have served on APSA committees (though that can reflect the fact that we are not asked to join such committees at the rate that we ought to be asked). We are much less likely to attend annual APSA meetings than are university professors in departments that grant Ph.Ds. Also, we are quite unlikely to serve on the editorial boards of professional journals (though again that may result from not being asked as much as we could be).

In short, the numbers suggest that as their careers evolve, LAC political scientists conclude that the organized profession does not meet their personal intellectual and teaching needs. There are advantages to that disaffection, to be sure-in particular, justifiable pride in how we have collectively forged a far more humanistic and interdisciplinary way of doing political science. As the other essays clearly demonstrate, this alternative is deeply interesting in its own right. But a disadvantage 


\section{TWO POLITICAL SCIENCES OR ONE?}

of cultivating it is a certain tunnel vision. We, instead, ought to value fully the vitality —and the utility for our teaching and personal intellectual nourishment-of contemporary political science and the institutions that generate it.

Rick Valelly is Claude C. Smith '14 Professor of Political Science at Swarthmore College, where he has taught since fall 1993. He can be reached at rvalell1@swarthmore.edu. 